\title{
Research on the Digitization of Manufacturing Will Enhance the Competitiveness of the Value Chain Based on Advantage Comparison
}

\author{
You-Qun Wu $\mathbb{D}^{1},{ }^{1}$ Huai-Xin Lu $\mathbb{D}^{1},{ }^{1}$ Xin-Lin Liao $\mathbb{D}^{1},{ }^{1}$ and Jia-Ming Zhu $\mathbb{D}^{1,2}$ \\ ${ }^{1}$ School of Economics, Anhui University of Finance and Economics, Bengbu, Anhui 233030, China \\ ${ }^{2}$ Institute of Quantitative Economics, Anhui University of Finance and Economics, Bengbu 233030, China \\ Correspondence should be addressed to Jia-Ming Zhu; zhujm1973@163.com
}

Received 14 March 2021; Revised 30 March 2021; Accepted 3 April 2021; Published 19 April 2021

Academic Editor: Shenggang Li

Copyright (C) 2021 You-Qun Wu et al. This is an open access article distributed under the Creative Commons Attribution License, which permits unrestricted use, distribution, and reproduction in any medium, provided the original work is properly cited.

\begin{abstract}
This paper uses WIOD data to calculate and analyze the dominant comparative advantage of Chinese manufacturing global value chain (GVC) based on the WWZ method and empirically studies the influence of digitization on the competitiveness of manufacturing GVC. The main findings are as follows: (1) The competitiveness of Chinese manufacturing GVC has been improved as a whole. The GVC competitiveness of different types of industries is quite different: GVC in middle- and low-knowledge-intensive industries have the highest competitiveness, while those with middle- and high-knowledge-intensive industries have the lowest competitiveness and apparent shortboard industries. (2) Digitization is conducive for enhancing the competitiveness of manufacturing GVC. In terms of industries, digitization has a significant positive effect on the GVC competitiveness of middle and high-knowledge-intensive industries but not on low knowledge ones. As for the sources of digital input, the positive effect is more outstanding. Also, it is more remarkable when it comes to the software and information technology service industry. (3) As for the mechanism of action, labor productivity is an effective way to improve the manufacturing GVC competitiveness digitally. Finally, after a robustness test, the positive effect of the digital input remains robust.
\end{abstract}

\section{Introduction}

The 2019 "Government Work Report" emphasizes: “The labor pains of economic transformation are increasingly prominent, and structural problems are obvious ... it is necessary to cultivate a number of advanced manufacturing industries globally and promote China's industries to move towards the high end of the global value chain (GVC)." The status of the international division of labor obtained by intensive work, low income of workers, and low profits of enterprises is still at the middle and low end of GVC, and issues such as industrial structure and path dependence have been continuously emerging. Since 2007, the proportion of current account surplus in China's GDP has decreased from $9.9 \%$ to less than $1 \%$. The expansion path of manufacturing with the advantages of low land, labor, and other factors is facing the risk of foreign technical barriers and industrial structure lock-in. Simultaneously, the added value of China's digital economy increased from 2.6 trillion yuan in 2005 to 35.8 trillion yuan in 2019, and its share of GDP rose from 14.2 percent to 36.2 percent, with an annual compound growth rate of 20.6 percent, making it the second-largest digital economy in the world. The rapid growth of the digital economy scale has become the key to deal with the downward pressure of the economy in China. The deep integration of the digital economy and China's economic society has become a new driving force of economic development (Data from the China ICT Institute's White Paper on China's Digital Economic Development (2020 Edition), in https://www.caict.ac.cn/ kxyj/qwfb/bps/202007/P020200703318256637020.pdf). 
The digital economy mainly includes industrial digitization and digital industrialization. Industrial digitization is based on digital technology, information data as the critical factor of production, and data empowerment as the mainline to achieve the industry's digital upgrading [1]. Artificial intelligence, big data, and cloud computing realized by digital technology have promoted the intellectualization, informatization, and technologicalization of traditional industries. Moreover, it effectively promotes the conversion of traditional industrial kinetic energy and collaborative innovation, nurtures new business forms, cultivates new engines of economic growth, and promotes the transformation and upgrading of traditional industries. At present, under the influence of reverse globalization and the global new crown epidemic, GVC is undergoing adjustment and remodeling, and China's manufacturing industry has ushered in new development opportunities. Improving the competitiveness of the China GVC manufacturing industry and obtaining more value distribution through the manufacturing industry's digitization has become an important subject worthy of further discussion.

To this end, this paper attempts to answer the following three questions through empirical research on the relationship between manufacturing digitization and GVC competitiveness: First, how does digitization affect manufacturing GVC competitiveness? Second, how is the impact of digitalization on manufacturing GVC competitiveness transmitted? Third, what is the impact of different types of digital inputs on the GVC competitiveness of the manufacturing industry?

\section{Literature Review and Mechanism Analysis}

2.1. Global Value Chains and Digitization. The proposal of GVC provides an important method for analyzing the organization and geographic characteristics of global trade, revealing the attributes including global industrial layout, value creation, as well as distribution process. Studies on GVC mainly focus on quantification and industrial upgrading [2]. In terms of quantitative research on GVC, as the global production network is becoming more and more perfect, and the intermediate processing trade is growing rapidly, the total value of statistics cannot reflect the real situation based on global "fragmented" trade. To explore the real added value of a country's participation in the division of international trade, Hummels et al. put forward the concept of vertical specialization (VS) and constructed a HIY model to measure the real participation of a country or region in the division of global value chain [3]. However, Hummels' original model ignored the possibility that importing countries may use a country's exports for processing reproduction (intermediate products) rather than for direct end-use. When calculating VS, there is a biased estimate of developing countries whose main industries are intermediate processing trade. Koopman et al. proposed a country's export decomposition method (KWW method) based on Hummels and subdivided the total trade exports of countries in GVC into four major types of value-added items [4], and further proposed that global value chain participation degree index used to reflect the degree of participation of a country or region (industry) in GVC. Since then, the WWZ method proposed by Wang et al. extended the KWW method, and applied it to the decomposition of total trade flows at the national sector level, bilateral trade level, and bilateral trade sector level [5]. In the follow-up study, the revised detailed comparative advantage index, forward participation index, and backward participation index were proposed to improve further the quantitative analysis system of global value chain. In terms of the GVC of industrial upgrading, scholars found that the main ways to achieve industrial upgrading through participation in the GVC division of labor system are: (1) The learning effect of GVC imports. In the process of embedding in GVC, GVC participating companies mainly import high-tech intermediate products. These intermediate products, as an important carrier of technology spillover, imply high-tech, advanced production concepts and capital goods input, enabling participating companies to learn through GVC imports. Effectively absorb advanced production technology and management concepts, thereby enterprises can reduce technology introduction costs, production costs, and learning costs [6]. Besides, under the stimulation of the learning-by-doing effect, enterprises promote the further improvement of production technology and management concepts through production, learning, and research; promote production efficiency; and promote industrial upgrading [7, 8]. (2) The effect of GVC export competition. As the division of labor in global production becomes more and more refined, a growing chorus of countries has joined them, and each country has played the role of trade processing [9]. The production of the same intermediate product is not monopolized by one country, and countries compete with each other, resulting in substitution effects that increase their export pressures. However, this competitive pressure will force the intermediate manufacturing industry to carry out research and development actively, realize the innovation of production technology, improve production efficiency, and ultimately promote industrial upgrading $[10,11]$.

In the rapid development of the digital economy, research institutions and scholars in various countries have successively carried out research on the important role of digitalization. Most of the related documents involved in digitalization in the early stage are more inclined to be information-based, mostly focusing on the investment of single information and communication technology (ICT) as the research object [12], while digitization is a new generation of information technology applications focusing on artificial intelligence, big data, computing, and the Internet of things [13]. A research on the relationship between digitization and GVC has gradually become the focus of scholars' discussion. For example, Manyika et al. studied the promotion of digitalization in different types of industries and believed that digitalization could promote basic industries to climb to the high end of the value chain, and found that digitalization has a more significant promotion effect on the production efficiency of small and mediumsized enterprises [14]. Pató et al. conducted a research on 
digitalization and American manufacturing, and believed that the manufacturing industry has reduced production and operating costs through digital services and improved the manufacturing value chain [15]. Z. Z. Du and J. X. Du believed that the fourth industrial revolution characterized by digital technology has promoted the transformation of traditional manufacturing, decomposition, integration, and innovation of GVC, and changed the added value of each link of GVC [16]. Shen and Jin believed that the digital value creation method is to innovate the distribution of international trade benefits through substitution and embedding of digital products, which will affect the division of labor in the global value chain [17]. He used the WIOD database to investigate the effect of digitalization on the upgrading and reconstruction of China's manufacturing industry and found that increasing digital investment can significantly promote the high-end manufacturing industry [18]. Acemoglu et al. examined the impact of digital technology on enterprises from the perspective of intelligence and found that enterprises that embed more intelligence could obtain more added value [19].

2.2. Analysis of the Mechanism of Digitization and Manufacturing GVC. With reference to the analytical framework of Hausmann et al.'s "cost discovery" model, the general theoretical model of GVC established by Qiu et al. was aimed at discussing the production efficiency of a country's export sector from a micro perspective and explore the factors that affect the GVC of the manufacturing industry $[20,21]$. Assuming that technological progress is Hicks neutral and that the scale reward remains the same, the Cobb-Douglas production function of a country's export sector is shown as follows:

$$
Y=A K^{a} L^{b} N^{c} .
$$

Here, $K, L$, and $N$ represents capital, labor, and other resources, respectively. Referring to the total factor productivity formula, the technical level as $F=Y /\left(K^{a} L^{b} N^{c}\right)=A, A$ means combining these technical production parameters of the factors, $0 \leq A \leq k$, and $A$ uniform distribution, $k$, represents the technological endowment of a country. The larger the value of $k$, the higher the potential production efficiency of a country's enterprises, which means that the enterprise can complete products with high technical complexity, which is beneficial to the enterprise in the GVC high-value-added link. Assumption $k$ depends on a country's external knowledge $O$ (such as trade, FDI technology spillovers, etc.), internal knowledge $I$ (such as capital deepening, human capital, etc.), and other factors $D$ (such as digital input, marketization, etc.) that affect the two. That is, " $k=F(O, I, D)$." According to the principle of "cost discovery," when producing new products, enterprises $i$ can choose to either research and develop independently or imitate existing similar products simply.

Assuming that the optimal production efficiency of existing products is $A^{M}$, and the imitation efficiency of enterprise $i$ is $t, 0<t<1 . A_{i}$ is the production efficiency level of the $i$ enterprise. If $A_{i} \geq t A^{M}$, the enterprise $i$ would choose independent research and development, otherwise it would choose to imitate other enterprises' products.

Assuming that currently there are $M$ companies in total, and $E\left(A^{M}\right)=k M /(M+1)$, then the probability that enterprise $i$ chooses to imitate and the expected technical parameters are

$$
\begin{aligned}
& \operatorname{prob}\left(A_{i} \leq t A^{M}\right)=\frac{t E\left(A^{M}\right)}{k}=\frac{t M}{(M+1)}, \\
& E\left(A_{i} \mid A_{i} \leq t A^{M}\right)=t E\left(A^{M}\right)=\frac{k t M}{(M+1)} .
\end{aligned}
$$

In the same way, we can get the probability and the expected value of technical parameters for the independent research and development of $i$ enterprise:

$$
\begin{gathered}
\operatorname{prob}\left(A_{i} \geq t A^{M}\right)=1-\frac{t E\left(A^{M}\right)}{k}=1-\frac{t M}{(M+1)}, \\
E\left(A_{i} \mid A_{i} \geq t A^{M}\right)=\frac{1}{2}\left[k+t E\left(A^{M}\right)\right]=\frac{k}{2}\left(1+\frac{t M}{M+1}\right) .
\end{gathered}
$$

Therefore, the expected value of technical parameter $A$ of the export department can be obtained:

$$
E(A)=\frac{k}{2}\left[1+\left(\frac{t M}{1+M}\right)^{2}\right] .
$$

Substituting equation (5) into equation (3) can elicit the production efficiency level of a country's export sector and then construct the function of the influencing factors of sector GVC:

$$
\frac{E(Y)}{L}=\frac{k}{2}\left[1+\left(\frac{t M}{1+M}\right)^{2}\right]\left(\frac{K}{L}\right)\left(\frac{N}{L}\right)=\frac{1}{2} F(O, I, D)\left[1+\left(\frac{t M}{1+M}\right)^{2}\right]\left(\frac{K}{L}\right)\left(\frac{N}{L}\right) .
$$

Formula (6) shows that the export sector's productivity (which determines GVC competitiveness) mainly depends on external knowledge, internal knowledge, and other elements that affect both. It can be inferred from this that when digital embedding in the export sector can affect any of the determinants mentioned above, it will impact the export sector's production efficiency. That is, it will have an impact on the GVC competitiveness of the export sector. The same is true for expanding to the industrial level. Based on existing research, this paper believes that digitization mainly affects 
the competitiveness of manufacturing GVC through the following three ways.

2.2.1. The Cost Effect of Digitization. In international trade, both sides of the trade are often subjected to spatial geographical distance, language and culture, and higher transaction costs such as search and negotiation. The high transaction costs restrict the free flow of elements such as intermediate input and high-end talents across regions. Digitalization has realized data informatization, application platformization, and quantification of information seas with digital technology and related services based on the infrastructure built in the "cloud," breaking the time and space constraints of all aspects of international trade, reducing the difficulty of searching for trading partners, promoting the expansion of bilateral markets into multilateral markets, and promoting enterprises to form economies of scale and scope while reducing intermediate transaction costs. At the same time, enterprises can efficiently grasp market transactions through big data analysis and then realize efficient matching to serve market competition and product pricing. In addition, digital technology based on the Internet also follows Moore's law [17]. According to Moore's Law, computer chips' processing performance doubles approximately every 18 months, and prices are halved, meaning that advances in digital technology will increasingly reduce production costs and enhance competitive advantage.

2.2.2. The Configuration Effect of Digitalization. Digital technology has the characteristics of high replicability, high versatility, inclusiveness, and inclusiveness, which can significantly enhance the liquidity of enterprise production factors, and enable material resources, information resources to achieve precise allocation at lower cost and higher efficiency [1]. Enterprises use big data, artificial intelligence, blockchain, Internet of things, and other automation, information, and platform applications, to achieve partial replacement of the original nonautomated, noninformation, nonplatform, and other low-end production factors, to optimize the intelligent manufacturing capacity of enterprises, and to improve the production efficiency of enterprises and the use of domestic production factors in other countries' final product production [22, 23]. The continuous embedding of digital technology in traditional industries is conducive for the improvement of industrial service channels, the realization of production, sales, service, and other links of platform and automation to meet consumer and market preferences [24]. Moreover, in the lowend production link, the replacement of low-end labor to achieve an increase in the average quality of labor and the proportion of high-level production factors is conducive for the industry to increase total factor productivity and return on capital, expand the industry's competitive advantage, and realize the high-end GVC [25].

2.2.3. Digital Synergy. The new development momentum brought about by digitalization, such as $5 \mathrm{G}$, big data, artificial intelligence, and the Internet of Everything, has dramatically changed the traditional business model. As the division of GVC becomes more detailed and more in-depth, a growing number of countries are integrating enterprises into global production networks. Digital technologies, such as artificial intelligence and interconnection platforms, have brought about "face-to-face" forms of communication, such as web conferencing, remote assistance, and webcasting, eliminating the communication constraints of space distance; realizing enterprise data sharing between different countries and different value chain links; promoting collaborative research and development, synchronous decisionmaking; and enhancing efficiency of cooperative division of labor [26, 27]. The real-time interaction and automation function brought about by digitization can effectively optimize the control of the optimal production combination of the products; automatically realize the production distribution, quality inspection, and improve the efficiency of labor division; and reduce the cost of cooperative operation. Big data analysis brought about by digitization can significantly enrich the amount of decision-making information for enterprises and give enterprises the ability to respond to market changes flexibly, to reduce decision-making risks for decision-makers, to expand competitive enterprise advantages, and to realize the improvement of production and operation efficiency $[28,29]$.

To sum up, although the existing kinds of literature have recognized the impact of digitization on GVC division of labor, the empirical study on the relationship between digitization and GVC needs to be further explored. These are the following aspects that deserve improvement:

First, there are many documents choosing GVC participation or status index when measuring GVC division of labor, but few scholars have considered the perspective of industrial competitiveness (advantage). Because of this, this paper's explanatory variables are measured by revealed comparative advantage index considering the competitiveness of industrial GVC, and the study of the relationship between digitalization and GVC opens up a new perspective, which, in turn, opens up a new perspective for the study of the relationship between digitalization and GVC.

Second, most of the literature still uses fixed telephone penetration rate, mobile phone penetration rate, computer penetration rate, broadband penetration rate, and other variables that lack specificity and timeliness when measuring digitalization. Although a few documents use more authoritative digital investment to measure, they are forced by data availability. The definition of digital investment is too small, and the possible impact on digitalization is estimated to be too small. It is only examined from the perspective of the total extent of digitalization. Because of this, this paper expands the definition of digital input in previous studies, distinguishes the sources and types of digital input, and further empirically explores the heterogeneous effects of digitalization from different sources and types.

Third, the existing literature rarely proposes specific transmission paths in analyzing the impact of digitalization on manufacturing GVC. In view of this, this paper will further explore the transmission path of digital to manufacturing GVC in the empirical part. 
Fourth, most of the literature focuses on the national or provincial level. This treatment is too macro to capture more micro-level information, and it is challenging to form industry-specific policy enlightenment. Because of this, this paper focuses on the industry level, deeply analyzes the digital investment and GVC competitiveness of manufacturing and subdivision industries, and the policy enlightenment proposed is more pertinent and feasible for the industry.

Therefore, the main contributions of this paper are as follows: first, from the perspective of revealed comparative advantage to analyze the impact of digitization on the division of labor and the transmission path of manufacturing GVC, this paper enriches the relevant research of digitization and GVC. Second, the paper expands the definition of digitization in previous studies, and defines and measures digitization from three angles: software and information technology services, electronic communication and optical manufacturing and telecommunications, and the competitiveness of the industry from the perspective of GVC in different knowledge-intensive industries. Third, by dividing domestic, international, and various types of digital input, the heterogeneity of the influence of different digital inputs on manufacturing GVC is analyzed.

\section{Research Methods and Data}

\subsection{Research Methods}

3.1.1. The Measurement Basis of GVC-Related Indicators. At present, the decomposition method based on the added value of international trade can fully consider the segmentation process of global product production and reflect the real added value of a country's industrial exports. Among them, the WWZ method decomposes the international trade flow into foreign added value, export of added value, return of domestic added value, and pure double calculation according to the way of absorption of international trade products and the place of final use, which realizes the detailed analysis of the flow of added value in all aspects of international trade [30]. This paper uses the WWZ method to reveal the value-added flow of GVC through the input-output model of the three countries and then obtains the calculation basis of GVC-related indexes. The method is briefly described in Table 1 .

Among them, the subscripts s, $r$, and t represent $S, R$, and $T$ states, respectively. $Z$ represents the intermediate product input matrix. $Y$ represents the end product use matrix. VA is the added value row vector. $C$ represents the total output column vector. The superscript "/" means matrix transpose. $Z_{\mathrm{sr}}, Y_{\mathrm{sr}}, \mathrm{VA}_{\mathrm{s}}$, and $C_{\mathrm{s}}$ represent $\mathrm{S}$ country's exports of products used by the country $R$ as intermediate products, as for the end-use part, $S$ country's added value and output, respectively. From the perspective of the use direction of a country's input and output, there is the following balance:

$$
\left[\begin{array}{c}
Z_{\mathrm{ss}}+Z_{\mathrm{sr}}+Z_{\mathrm{st}} \\
Z_{\mathrm{rs}}+Z_{\mathrm{rr}}+Z_{\mathrm{rt}} \\
Z_{\mathrm{ts}}+Z_{\mathrm{tr}}+Z_{\mathrm{tt}}
\end{array}\right]+\left[\begin{array}{c}
Y_{\mathrm{ss}}+Y_{\mathrm{sr}}+Y_{\mathrm{st}} \\
Y_{\mathrm{rs}}+Y_{\mathrm{rr}}+Y_{\mathrm{rt}} \\
Y_{\mathrm{ts}}+Y_{\mathrm{tr}}+Y_{\mathrm{tt}}
\end{array}\right]=\left[\begin{array}{c}
C_{\mathrm{s}} \\
C_{\mathrm{r}} \\
C_{\mathrm{t}}
\end{array}\right] .
$$

Based on the input-output model, the input coefficient matrix is defined as $A \equiv Z(\widehat{C})^{-1}$, and the superscript " $\wedge$ " means diagonalization, then:

$$
\left[\begin{array}{ccc}
A_{\mathrm{ss}} & A_{\mathrm{sr}} & A_{\mathrm{st}} \\
A_{\mathrm{rs}} & A_{\mathrm{rr}} & A_{\mathrm{rt}} \\
A_{\mathrm{ts}} & A_{\mathrm{tr}} & A_{\mathrm{tt}}
\end{array}\right]\left[\begin{array}{c}
C_{\mathrm{s}} \\
C_{\mathrm{r}} \\
C_{\mathrm{t}}
\end{array}\right]+\left[\begin{array}{c}
Y_{\mathrm{ss}}+Y_{\mathrm{sr}}+Y_{\mathrm{st}} \\
Y_{\mathrm{rs}}+Y_{\mathrm{rr}}+Y_{\mathrm{rt}} \\
Y_{\mathrm{ts}}+Y_{\mathrm{tr}}+Y_{\mathrm{tt}}
\end{array}\right]=\left[\begin{array}{c}
C_{\mathrm{s}} \\
C_{\mathrm{r}} \\
C_{\mathrm{t}}
\end{array}\right] .
$$

The classical Lyontief formula can be obtained by adjusting formula (8) with input coefficient matrix:

$$
\left[\begin{array}{lll}
B_{\mathrm{ss}} & B_{\mathrm{sr}} & B_{\mathrm{st}} \\
B_{\mathrm{rs}} & B_{\mathrm{rr}} & B_{\mathrm{rt}} \\
B_{\mathrm{ts}} & B_{\mathrm{tr}} & B_{\mathrm{tt}}
\end{array}\right]+\left[\begin{array}{c}
Y_{\mathrm{ss}}+Y_{\mathrm{sr}}+Y_{\mathrm{st}} \\
Y_{\mathrm{rs}}+Y_{\mathrm{rr}}+Y_{\mathrm{rt}} \\
Y_{\mathrm{ts}}+Y_{\mathrm{tr}}+Y_{\mathrm{tt}}
\end{array}\right]=\left[\begin{array}{c}
C_{\mathrm{s}} \\
C_{\mathrm{r}} \\
C_{\mathrm{t}}
\end{array}\right] .
$$

Among them, $B\left(B=(\widehat{I}-A)^{-1}\right)$ is the inverse matrix of Leontief. According to formula (9), the intermediate products exported from country $\mathrm{S}$ to country $\mathrm{R}$ can be decomposed according to the final absorption location and absorption channel as follows:

$$
\begin{aligned}
Z_{\mathrm{sr}}= & A_{\mathrm{sr}} C_{\mathrm{r}}=A_{\mathrm{sr}} B_{\mathrm{rs}} Y_{\mathrm{ss}}+A_{\mathrm{sr}} B_{\mathrm{rs}} Y_{\mathrm{sr}}+A_{\mathrm{sr}} B_{\mathrm{rs}} Y_{\mathrm{st}}+A_{\mathrm{sr}} B_{\mathrm{rr}} Y_{\mathrm{rs}} \\
& +A_{\mathrm{sr}} B_{\mathrm{rr}} Y_{\mathrm{rr}}+A_{\mathrm{sr}} B_{\mathrm{rr}} Y_{\mathrm{rt}}+A_{\mathrm{sr}} B_{\mathrm{rt}} Y_{\mathrm{ts}}+A_{\mathrm{sr}} B_{\mathrm{rt}} Y_{\mathrm{tr}} \\
& +A_{\mathrm{sr}} B_{\mathrm{rt}} Y_{\mathrm{tt}}
\end{aligned}
$$

Similarly, intermediate products can be decomposed according to different sources of added value and end-use. First, define the value-added coefficient $V_{\mathrm{s}} \equiv V A_{\mathrm{s}}\left(C_{\mathrm{s}}\right)^{-1}$. Similarly, we can get $V_{\mathrm{r}}$ and $V_{\mathrm{t}}$. The value-added coefficient matrix is the following formula:

$$
\mathrm{VB}=\left[\begin{array}{lll}
V_{\mathrm{s}} & V_{\mathrm{r}} & V_{\mathrm{t}}
\end{array}\right]\left[\begin{array}{lll}
B_{\mathrm{ss}} & B_{\mathrm{sr}} & B_{\mathrm{st}} \\
B_{\mathrm{rs}} & B_{\mathrm{rr}} & B_{\mathrm{rt}} \\
B_{\mathrm{ts}} & B_{\mathrm{tr}} & B_{\mathrm{tt}}
\end{array}\right] .
$$

The result of the above formula is a $1 * 3$ matrix, and each element is 1 . For country S, we obtain as follows:

$$
V_{\mathrm{s}} B_{\mathrm{ss}}+V_{\mathrm{r}} B_{\mathrm{rs}}+V_{\mathrm{t}} B_{\mathrm{ts}}=u, \quad u=(1,1, \ldots, 1) .
$$

$E_{\mathrm{sr}}$ represents the intermediate products and final exports of country $S$ exported to country R. $E_{\mathrm{sr}}=A_{\mathrm{sr}} C_{\mathrm{r}}+Y_{\mathrm{sr}}$. Similarly, we can get $E_{\mathrm{st}}$. Then, the total export of country $S$ can be expressed as: $E_{\mathrm{s}}=E_{\mathrm{sr}}+E_{\mathrm{st}}=A_{\mathrm{sr}} C_{\mathrm{r}}+Y_{\mathrm{sr}}+A_{\mathrm{st}} C_{\mathrm{r}}+Y_{\mathrm{st}}$. Therefore, formula (8) can be rewritten as follows:

$$
\left[\begin{array}{ccc}
A_{\mathrm{ss}} & 0 & 0 \\
0 & A_{\mathrm{rr}} & 0 \\
0 & 0 & A_{\mathrm{tt}}
\end{array}\right]\left[\begin{array}{c}
C_{\mathrm{s}} \\
C_{\mathrm{r}} \\
C_{\mathrm{t}}
\end{array}\right]+\left[\begin{array}{c}
Y_{\mathrm{ss}}+E_{\mathrm{s}} \\
Y_{\mathrm{rr}}+E_{\mathrm{r}} \\
Y_{\mathrm{tt}}+E_{\mathrm{t}}
\end{array}\right]=\left[\begin{array}{c}
C_{\mathrm{s}} \\
C_{\mathrm{r}} \\
C_{\mathrm{t}}
\end{array}\right] .
$$

Formula (13) can be adjusted to obtain Leontief s classic formula and the Leontief inverse matrix of the single country model. Let $L_{\mathrm{ss}}$ represent the domestic Leontief inverse matrix of 
TABle 1: Input-output model for three countries.

\begin{tabular}{|c|c|c|c|c|c|c|c|c|}
\hline \multirow{2}{*}{ Inputs } & \multirow{2}{*}{ Outputs } & \multicolumn{3}{|c|}{ Intermediate use } & \multicolumn{3}{|c|}{ Final use } & \multirow{2}{*}{ Total outputs } \\
\hline & & $S$ states & $\mathrm{R}$ states & $\mathrm{T}$ states & $S$ states & $\mathrm{R}$ states & T states & \\
\hline \multirow{3}{*}{ Middle inputs } & $\mathrm{S}$ states & $Z_{\mathrm{ss}}$ & $Z_{\mathrm{sr}}$ & $Z_{\text {st }}$ & $Y_{\mathrm{ss}}$ & $Y_{\text {sr }}$ & $Y_{\text {st }}$ & $C_{\mathrm{s}}$ \\
\hline & $\mathrm{R}$ states & $Z_{\mathrm{rs}}$ & $Z_{\mathrm{rr}}$ & $Z_{\mathrm{rt}}$ & $Y_{\mathrm{rs}}$ & $Y_{\mathrm{rr}}$ & $Y_{\mathrm{rt}}$ & $C_{\mathrm{r}}$ \\
\hline & $\mathrm{T}$ states & $Z_{\mathrm{ts}}$ & $Z_{\mathrm{tr}}$ & $Z_{\mathrm{tt}}$ & $Y_{\mathrm{ts}}$ & $Y_{\mathrm{tr}}$ & $Y_{\mathrm{tt}}$ & $C_{\mathrm{t}}$ \\
\hline \multirow{2}{*}{\multicolumn{2}{|c|}{$\begin{array}{l}\text { Value added } \\
\text { Total inputs }\end{array}$}} & V.A.s & $\mathrm{VA}_{\mathrm{r}}$ & $\mathrm{VA}_{\mathrm{t}}$ & - & - & - & - \\
\hline & & $\left(F_{\mathrm{s}}\right)^{\prime}$ & $\left(F_{\mathrm{r}}\right)^{\prime}$ & $\left(F_{\mathrm{t}}\right)^{\prime}$ & - & - & - & - \\
\hline
\end{tabular}

country S, $L_{\mathrm{ss}}=\left(I-A_{\mathrm{sS}}\right)^{-1}$, and we can obtain the Leontief inverse matrix of country $\mathrm{R}$ and country $\mathrm{T}$. According to formula (13), intermediate products exported from country $S$ to country $\mathrm{R}$ can be obtained as follows:

$$
Z_{\mathrm{sr}}=A_{\mathrm{sr}} C_{\mathrm{r}}=A_{\mathrm{sr}} L_{\mathrm{rr}} Y_{\mathrm{sr}}+A_{\mathrm{sr}} L_{\mathrm{rr}} E_{\mathrm{r}}
$$

Combining formulas (10), (12), and (14), the decomposition of total exports from country $S$ to country $R$ can be obtained as follows:

$$
\begin{aligned}
E_{\mathrm{sr}}= & A_{\mathrm{sr}} C_{\mathrm{r}}+Y_{\mathrm{sr}}=\left(V_{\mathrm{s}} B_{\mathrm{ss}}\right)^{\prime} Y_{\mathrm{sr}}+\left(V_{\mathrm{s}} B_{\mathrm{rs}}\right)^{\prime} Y_{\mathrm{sr}}+\left(V_{\mathrm{t}} B_{\mathrm{ts}}\right)^{\prime} Y_{\mathrm{sr}}+\left(V_{\mathrm{s}} B_{\mathrm{ss}}\right)^{\prime}\left(A_{\mathrm{sr}} C_{\mathrm{r}}\right) \\
& +\left(V_{\mathrm{s}} B_{\mathrm{ss}}\right)^{\prime}\left(A_{\mathrm{sr}} C_{\mathrm{r}}\right)+\left(V_{\mathrm{r}} B_{\mathrm{rs}}\right)^{\prime}\left(A_{\mathrm{sr}} C_{\mathrm{r}}\right)+\left(V_{\mathrm{t}} B_{\mathrm{ts}}\right)^{\prime}\left(A_{\mathrm{sr}} C_{\mathrm{r}}\right) \\
= & \left(V_{\mathrm{s}} B_{\mathrm{ss}}\right)^{\prime} Y_{\mathrm{sr}}+\left(V_{\mathrm{s}} L_{\mathrm{ss}}\right)^{\prime}\left(A_{\mathrm{sr}} B_{\mathrm{rr}} Y_{\mathrm{rr}}\right)+\left(V_{\mathrm{s}} L_{\mathrm{ss}}\right)^{\prime}\left(A_{\mathrm{sr}} B_{\mathrm{rt}} Y_{\mathrm{tt}}\right)+\left(V_{\mathrm{s}} L_{\mathrm{ss}}\right)^{\prime}\left(A_{\mathrm{sr}} B_{\mathrm{rr}} Y_{\mathrm{rt}}\right) \\
& +\left(V_{\mathrm{s}} L_{\mathrm{ss}}\right)^{\prime}\left(A_{\mathrm{sr}} B_{\mathrm{rt}} Y_{\mathrm{tr}}\right)+\left(V_{\mathrm{s}} L_{\mathrm{ss}}\right)^{\prime}\left(A_{\mathrm{sr}} B_{\mathrm{rr}} Y_{\mathrm{rs}}\right)+\left(V_{\mathrm{s}} L_{\mathrm{ss}}\right)^{\prime}\left(A_{\mathrm{sr}} B_{\mathrm{rt}} Y_{\mathrm{ts}}\right)+\left(V_{\mathrm{s}} L_{\mathrm{ss}}\right)^{\prime}\left(A_{\mathrm{sr}} B_{\mathrm{rs}} Y_{\mathrm{ss}}\right) \\
& +\left(V_{\mathrm{s}} L_{\mathrm{ss}}\right)^{\prime}\left[A_{\mathrm{sr}} B_{\mathrm{rs}}\left(Y_{\mathrm{rr}}+Y_{\mathrm{st}}\right)\right]+\left(V_{\mathrm{s}} B_{\mathrm{ss}}-V_{\mathrm{s}} L_{\mathrm{ss}}\right)^{\prime}\left(A_{\mathrm{sr}} X_{\mathrm{r}}\right)+\left(V_{\mathrm{r}} B_{\mathrm{rs}}\right)^{\prime} Y_{\mathrm{sr}}+\left(V_{\mathrm{r}} B_{\mathrm{rs}}\right)^{\prime}\left(A_{\mathrm{sr}} L_{\mathrm{rr}} Y_{\mathrm{rr}}\right) \\
& +\left(V_{\mathrm{r}} B_{\mathrm{rs}}\right)^{\prime}\left(A_{\mathrm{sr}} L_{\mathrm{rr}} E_{\mathrm{r}}\right)+\left(V_{\mathrm{t}} B_{\mathrm{ts}}\right)^{\prime} Y_{\mathrm{sr}}+\left(V_{\mathrm{t}} B_{\mathrm{ts}}\right)^{\prime}\left(A_{\mathrm{sr}} L_{\mathrm{rr}} Y_{\mathrm{rr}}\right)+\left(V_{\mathrm{t}} B_{\mathrm{ts}}\right)^{\prime}\left(A_{\mathrm{sr}} L_{\mathrm{rr}} E_{\mathrm{r}}\right) .
\end{aligned}
$$

The above formula substitutes the value-added coefficient into the decomposition of international intermediate products. According to the added value of export and the place of final use, it can be divided into sixteen added value and repeated calculation parts. The structure diagram of the total trade accounting algorithm is shown in Figure 1.

\subsubsection{The Method of Calculating GVC Competitiveness of} China's Manufacturing Industry. In the calculation of trade value added based on the input-output model, it is natural to involve the calculation of a country's Revealed Comparative Advantage (RCA) index. The RCA index reflects the comparative advantage of a certain industry in a country and the actual result formed by the competitive advantage. And, it is one of the important indicators to measure the competitiveness (advantage) of GVC in the industry. RCA index is equal to the ratio of the export value of a country's industrial production to its total export product divided by the ratio of the global export value of the industrial product to the total export value of the product. Based on the WWZ method, Wang et al. comprehensively considered the division of domestic and international production in export production, excluded the pure double calculation in total export and the part of foreign added value, and revised the traditional RCA index [5]. The formula is as follows:

$$
\mathrm{RCA}_{-} \mathrm{VA}=\frac{\mathrm{DV}_{s i} / \sum_{s=1}^{m} \mathrm{DV}_{s i}}{\sum_{i=1}^{m} \mathrm{DV}_{s i} / \sum_{i=1}^{m} \sum_{s=1}^{n} \mathrm{DV}_{s i}} .
$$

Among them, $\mathrm{DV}_{s i}$ represents the added value of domestic exports of the $i$ industry in country S. $\sum_{s=1}^{m} \mathrm{DV}_{s i}$ represents the sum of the added value of domestic exports of all industries in country S. $\sum_{i=1}^{m} \mathrm{DV}_{s i}$ represents the added value of domestic exports of the global $i$ industry. $\sum_{i=1}^{m} \sum_{s=1}^{n} \mathrm{DV}_{s i}$ represents the sum of the added value of domestic exports of all industries in the world. Generally speaking, the RCA index value is greater than 1, which indicates that the industry's trade export has a dominant comparative advantage and the international competitiveness is at the global upstream level. RCA index value is less than 1 , and the trade export of the industry has a dominant comparative disadvantage and does not have international competitiveness.

3.2. Data Sources. The raw data of manufacturing GVCrelated indicators involved in the paper are all from the World Input-Output Database (WIOD). WIOD is a widely used database when calculating GVC-associated indicators. The latest 2016 edition of the database covers 56 industry datasets from 43 economies around the world, with consistent statistical caliber and reliable data sources.

\section{Dynamic Evolution of China's Manufacturing GVC Competitiveness}

Figure 2 shows a horizontal comparative analysis of the RCA index between Chinese manufacturing and other major 


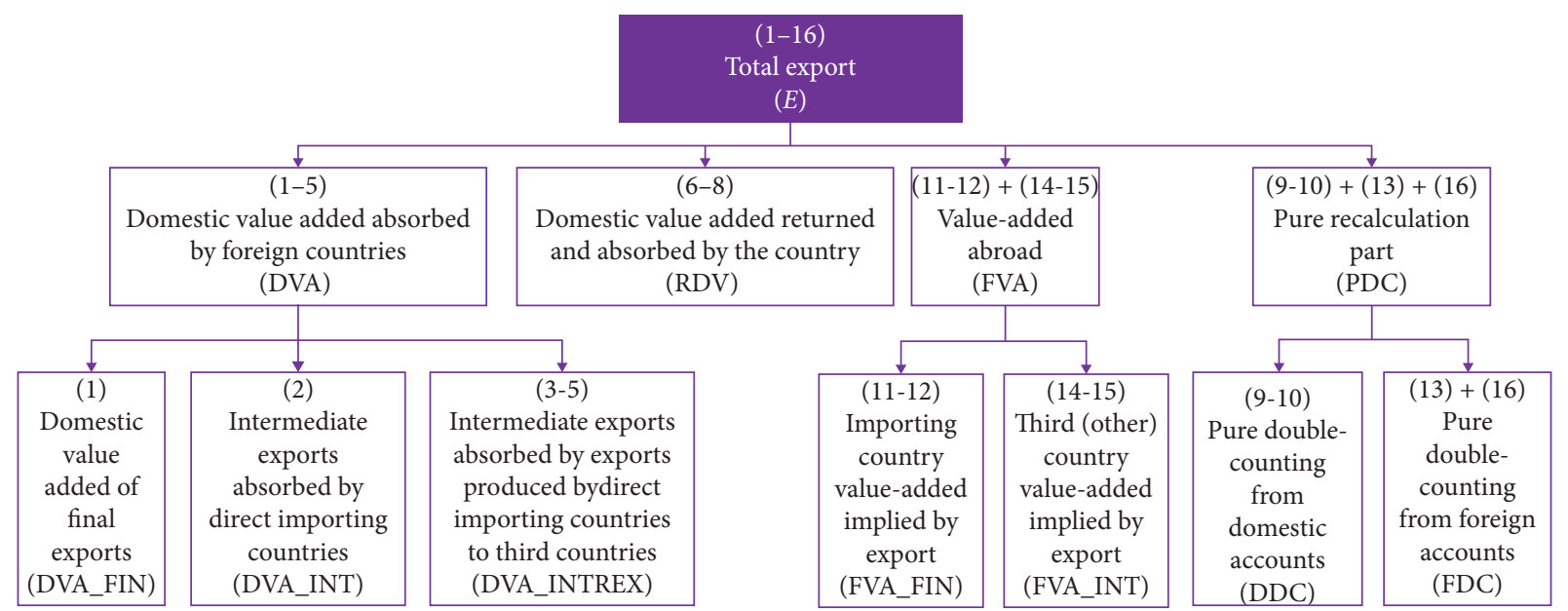

FIGURE 1: Conceptual framework of the total trade accounting method.

economies of the world (the United States, Japan, Germany, the United Kingdom, Russia, South Korea, Indonesia) from the perspective of explicit comparative advantage (RCA). As can be seen from Figure 2, China's manufacturing RCA index ranks top, among which the RCA ranking achieved steady growth from 2002 to 2007. It shows that China's manufacturing industry's international competitiveness is steadily improving. China's RCA ranking declined in volatility from 2008 to 2014. Meanwhile, Indonesia, Japan, Germany, and South Korea have seen a significant rise in the RCA index. This result shows that in the post-financial crisis era, the "return of investment" of developed countries, industrial transfer, and the rise of industrialization in developing countries have weakened the GVC competition in China's manufacturing industry. In addition, from the RCA ranking, it can be found that the manufacturing sector in Russia, Britain, and the United States have been seriously hollowed out, with China, Japan, Germany, and Korea having significant competitive advantages in manufacturing.

The above analysis results are based on the overall RCA index ranking of China's manufacturing industry. It is necessary to analyze the RCA index of China's manufacturing industry in more detail to understand the micro-level status of China's manufacturing GVC competitiveness. Therefore, this section conducts a horizontal and vertical comparative analysis of the RCA index from the manufacturing subndustry level, forming a more detailed and three-dimensional understanding of the competitive advantages of manufacturing GVC.

Figures 3-5 show the RCA ranking of China's manufacturing subdivisions in the same type of industry in 43 countries around the world, disaggregated by industry knowledge intensity (Here, we learn from $\mathrm{He}$ 's manufacturing industry classification method and classify the subindustries according to their knowledge intensity. Among them, low-knowledge-intensive industries include C05, C06, C07, C08, C09, medium- and low-knowledgeintensive industries include $\mathrm{C} 10, \mathrm{C} 11, \mathrm{C} 12, \mathrm{C} 13, \mathrm{C} 14, \mathrm{C} 15$, C16, C22, and medium-, and high-knowledge-intensive industries include C17, C18, C19, C20, C21.). It can be seen from Figure 3 that the phenomenon of "polarization" in lowknowledge-intensive industries, namely, textile, clothing, and leather products manufacturing (C06), has the most prominent RCA. After 2003, textile, clothing, and leather products manufacturing RCA ranked second in the world. The RCA of the printing and record media reproduction (C09) industry plummeted after 2002, once fell to 26 back in 2008 , and the ranking is still low. Wood products processing (C07) and paper products' (C08) RCA ranked steadily, ranked in about the 15th place. RCA in the food, beverage, and tobacco industries (C05) declined after 2008, ranked around 23. We can get the following findings from Figure 4. High stability in RCA in low- and medium-level knowledgeintensive industries, the chemical raw materials and chemical products manufacturing (C11), primary metal products industry (C15), and furniture and other manufacturing $(\mathrm{C} 22)$ ranked in the top 10 . The coking and petroleum industry $(\mathrm{C} 10)$, rubber and plastics industry (C13), and nonmetallic mineral products industry (C14) ranked around 15 . The primary pharmaceutical industry (C12) and the welding metal products (C16) ranked lower in about the 30th place. We can get the following findings from Figure 5. Except for the computer and electronic product manufacturing industry (C17), the RCA ranking is stable in the top 5, showing strong competitiveness. The RCA rankings of other industries have significant volatility. RCA rankings rise first and then fall. Among them, machinery and equipment manufacturing (C19) and other transportation equipment manufacturing (C21) are the most prominent, and RCA ranks lower. The automobile manufacturing industry (C20) still performs poorly after experiencing a steady upward phase, ranking around 25 .

In order to have a more intuitive vertical understanding of the competitive advantages of GVC in the manufacturing industry segment, figure 6 compares the RCA index mean from the perspective of the domestic manufacturing subdivision industry. We can get the following findings from Figure 6. In low-knowledge-intensive industries, textile, clothing, and leather products manufacturing (C06) and wood products processing $(\mathrm{C} 07)$ have a strong GVC division 


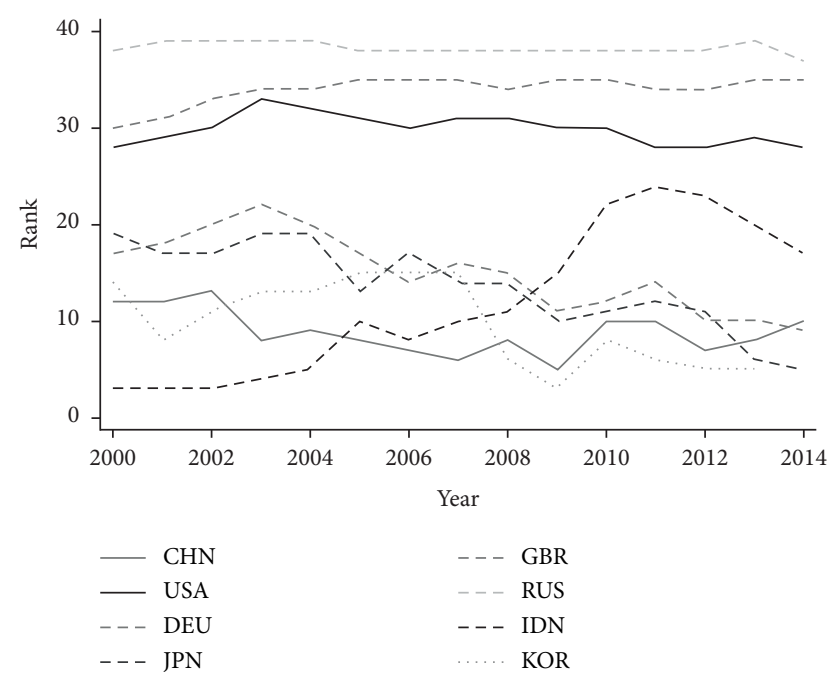

FIGURE 2: RCA global ranking of major world economies.

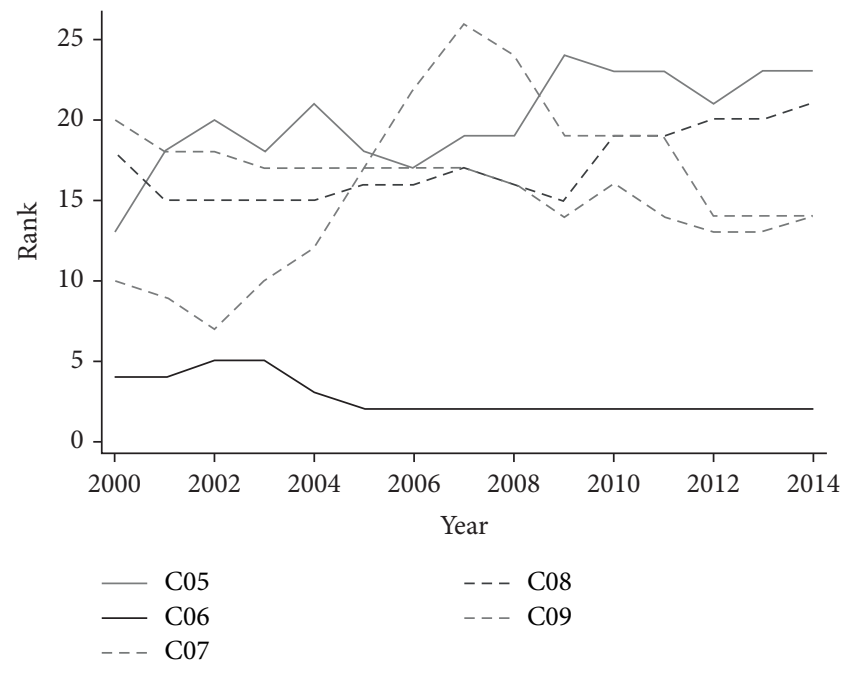

Figure 3: RCA global ranking of low-knowledge-intensive industries.

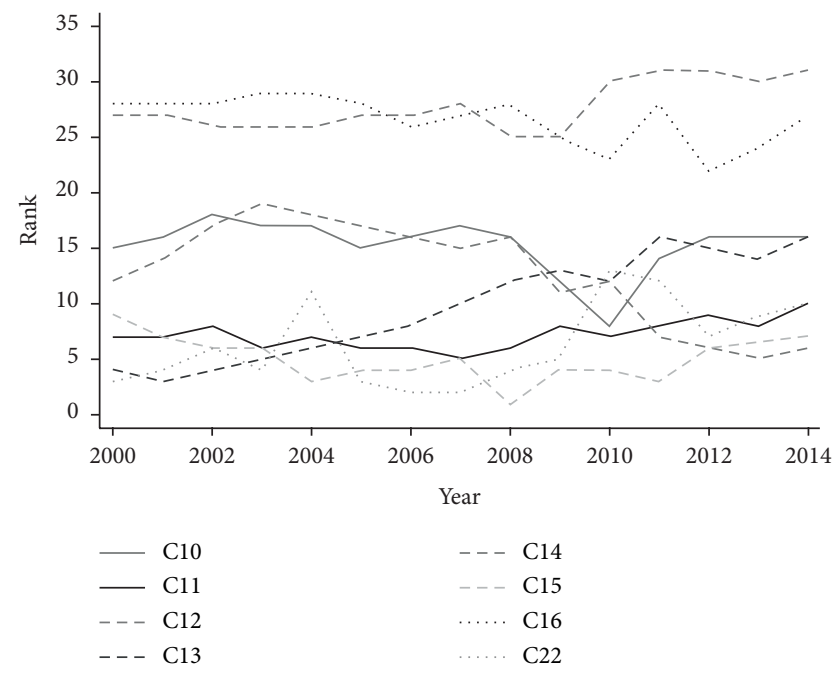

FIgURE 4: RCA global ranking of low- and medium-level knowledge-intensive industries.

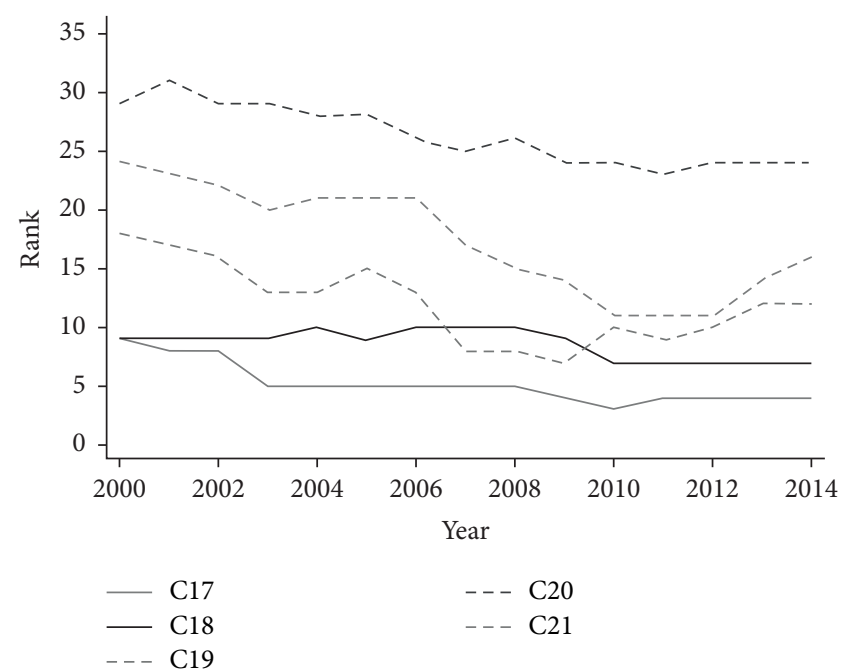

FIgURE 5: Global ranking RCA of high-knowledge-intensive industries.

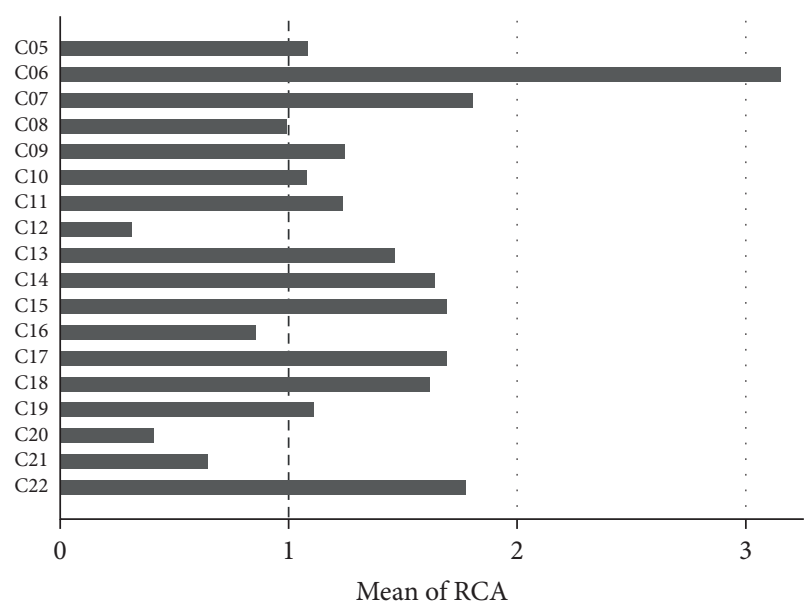

FIgURE 6: Average RCA index of China's manufacturing sector.

of labor competitiveness. RCA indices were 3.154 and 1.806, respectively. The paper and paper industry (C08) RCA index is below 1 , indicating that the competitiveness of GVC in the industry is below the global average, and at an unsatisfactory level. Although the remaining industries' RCA index is 1 , the RCA index for most industries is just 1 , and there is no significant competitive advantage. In the low- and mediumknowledge-intensive industries, except for the primary pharmaceutical industry (C12) and welded metal products (C16), the RCA index did not reach 1, and other industries all exceeded 1 , including rubber and plastics industry (C13) and nonmetallic mineral products. Industry (C14), primary metal products industry (C15), and furniture and other manufacturing (C22) RCA indexes are the most significant, reaching $1.465,1.640,1.694$, and 1.776 , respectively. The GVC competitiveness of these industries is not only at the global upstream level but also has significant competitive advantages. Among the high-knowledge-intensive industries, the RCA indexes of computer, electronic product manufacturing (C17), and electronic equipment 
manufacturing $(\mathrm{C} 18)$ are the most prominent. The RCA indexes are 1.694 and 1.618, respectively, indicating that the industry's GVC competitiveness is at the global upstream level and the advantages are significant. Machinery and equipment manufacturing (C19) RCA index has just reached 1 , and its value is 1.112 , which means that its GVC competitiveness is not significant. Other transportation equipment manufacturing industry (C21) and automobile manufacturing industries (C20) have poor GVC competitiveness performance. The RCA indexes are 0.409 and 0.646 , respectively, which means that these two industries are not only lower than the global average level but also have a significant gap.

It can be seen from the analysis results of China's manufacturing RCA index that the competitiveness of China's manufacturing GVC has improved and ranks high. In terms of industries, the GVC competitiveness of China's manufacturing industry is uneven. The low- and mediumknowledge-intensive industries have more significant GVC competitiveness and stable competitive advantages. The low-knowledge-intensive industries and medium- and high-knowledge-intensive industries have weak GVC competitiveness and significant shortcomings.

\section{Empirical Study on Digitalizing GVC Competitiveness in Manufacturing}

\subsection{Model Setting and Data Sources}

5.1.1. Model Setting. In order to empirically test the impact of digitalization on the competitiveness of China's manufacturing GVC and the heterogeneity of different digital effects, based on the model settings of $\mathrm{Li}$ and $\mathrm{He}$ $[31,32]$, the empirical model is constructed as follows:

$$
\mathrm{GVC}_{\_} \mathrm{RCA}_{i, t}=\beta_{0}+\beta_{1} \mathrm{GLO}_{-} \mathrm{DIGI} i, t+\beta \chi_{i, t}+v_{t}+\theta_{i}+\varepsilon_{i, t} \text {, }
$$

$$
\mathrm{GVC}_{\_\mathrm{RCA}}{ }_{i, t}=\beta_{0}+\beta_{1} \mathrm{CHN} \_\mathrm{DIGI} \mathrm{I}_{i, t}+\beta \chi_{i, t}+v_{t}+\theta_{i}+\varepsilon_{i, t} \text {, }
$$

$$
\mathrm{GVC}_{-\mathrm{RCA}_{i, t}}=\beta_{0}+\beta_{1} \mathrm{INT}_{-} \mathrm{DIGI} \mathrm{II}_{i, t}+\beta \chi_{i, t}+v_{t}+\theta_{i}+\varepsilon_{i, t} \text {, }
$$

$$
\mathrm{GVC}_{\_} \mathrm{RCA}_{i, t}=\beta_{0}+\beta_{1} \mathrm{TELE}_{-} \mathrm{DIGI} i, t+\beta \chi_{i, t}+v_{t}+\theta_{i}+\varepsilon_{i, t} \text {, }
$$

$$
\mathrm{GVC}_{-\mathrm{RCA}_{i, t}}=\beta_{0}+\beta_{1} \mathrm{SOFT}_{-} \mathrm{DIGI} \mathrm{I}_{i, t}+\beta \chi_{i, t}+v_{t}+\theta_{i}+\varepsilon_{i, t} \text {, }
$$

$$
\mathrm{GVC}_{\_} \mathrm{RCA}_{i, t}=\beta_{0}+\beta_{1} \mathrm{POST}_{-} \mathrm{DIGI} i, t+\beta \chi_{i, t}+v_{t}+\theta_{i}+\varepsilon_{i, t} .
$$

Among them, $i$ and $t$ represent industry and year, respectively; $\beta_{0}$ represents the intercept term; $v_{t}$ represents time fixed effect; $\theta_{i}$ represents the individual fixed effect; $\varepsilon_{i, t}$ represents the residual term; and $\chi_{i, t}$ represents the control variable.

The explained variable is measured by the RCA index, which can accurately reflect the competitive advantage of a country's industry in the GVC division of labor. And, it is an important indicator to measure the competitiveness of industry GVC. The core explanatory variable is digitization. Based on previous researches defining the digitization of the manufacturing industry [23-31], this paper expands the scope of digitization. The digitization of the manufacturing industry is defined as electronic communications and related information services in the manufacturing industry. Combined with data availability, it is measured by inputs from software and information technology services, electronic communications and optical manufacturing, and telecommunications.

In formula (17), the core explanatory variable GLO_DIGI $_{i, t}$ represents the global digital input used by industry $i$ in year $t$. In formula (18), CHN_DIGI $i, t$ represents the domestic digital input used by industry $i$ in year $t$. In formula (19), INT_DIGI $\mathrm{I}_{i, t}$ represents the international digital input used by industry $i$ in year $t$. In formula (20), TELE_DIGI ${ }_{i, t}$ represents the investment in the telecom industry used by industry $i$ in year $t$. In formula (21), SOFT_DIGI $i, t$ represents industry $i$, the amount of software and information technology service industry used. In formula (22), POST_DIGI $i, t$ represents the amount of electronic communication and optical manufacturing input used in the industry $i$ in year $t$. The control variables include overseas demand (ABORD), output scale (SCAL), capital stock (CAPI), and factor return (REPAY). In this industry, overseas demand is measured by industry export scale, output scale by industry output scale, capital stock by industry capital stock, and factor return by industry labor returns.

5.1.2. Data Sources. GVC-relevant raw data used in this paper have been taken from WIOD, and the raw data of the control variables from the social and economic accounts of the WIOD. And, standardized processing is done to eliminate the influence of dimension and order of magnitude. The sample data period is 2000-2014. The descriptive statistics of variables are shown in Table 2.

\subsection{Results Analysis}

5.2.1. Benchmark Model Test. Table 3 results from the estimation of formula (17) under the fixed effect of controlling industry and year using panel data fixed-effect model.

Table 3 shows that columns (1) to (5) are sequentially added to the control variables for regression. It can be found that the estimated coefficient of GLO_DIGID ${ }_{i, t}$ is always significantly positive, which proves that the increase in digital input in the manufacturing industry has a positive effect on the industry's apparent comparative advantage. The promotion effect means that the expansion of the manufacturing industry's digital scale is conducive for enhancing the competitiveness of manufacturing GVC. Besides, the estimated coefficients of REPAY ${ }_{i, t}$ and CAPIL $\mathrm{C}_{i, t}$ 
TABLE 2: Descriptive statistics for variables.

\begin{tabular}{lcccc}
\hline Variable & Mean & Minimum value & Maximum value & Standard deviation \\
\hline GVC_RCA $_{i, t}$ & 1.324 & 0.248 & 3.462 & 0.65 \\
GLO_DIGI $_{i, t}$ & $1.90 E+04$ & 137.769 & $6.50 E+05$ & $7.70 E+04$ \\
CHN_DIGI $_{i, t}$ & $1.80 E+04$ & 125.5 & $6.10 E+05$ & $7.10 E+04$ \\
INT_DIGI & $18, t$ & 12.269 & $4.70 E+04$ & 6616.215 \\
TELE_DIGI & 883.939 & 39.423 & 8815.904 & 1094.297 \\
SOFT_DIGI & 329.167 & 9.378 & 6046.861 & 725.394 \\
POST_DIGI & $2.4 E+04$ & 115.768 & $7.8 E+05$ & $9.7 E+04$ \\
ABORDI $_{i, t}$ & $2.70 E+04$ & 921.835 & $1.70 E+05$ & $3.00 E+04$ \\
SCALI $_{i, t}$ & $3.80 E+05$ & $2.10 E+04$ & $1.80 E+06$ & $4.00 E+05$ \\
CAPII $_{i, t}$ & $3.20 E+05$ & $2.00 E+04$ & $1.70 E+06$ & $2.90 E+05$ \\
REPAYI $_{i, t}$ & $2.20 E+05$ & $2.40 E+04$ & $9.30 E+05$ & $2.10 E+05$ \\
\hline
\end{tabular}

TABLE 3: Baseline regression estimates.

\begin{tabular}{|c|c|c|c|c|c|}
\hline Variable & (1) & (2) & (3) & $(4)$ & (5) \\
\hline $\mathrm{GLO}_{-} \mathrm{IIGI}_{i, t}$ & $\begin{array}{c}0.173^{* * *} \\
{[4.10]}\end{array}$ & $\begin{array}{c}0.101^{* *} \\
{[2.10]}\end{array}$ & $\begin{array}{c}0.133^{* *} \\
{[2.45]} \\
\end{array}$ & $\begin{array}{c}0.229^{* * *} \\
{[3.99]}\end{array}$ & $\begin{array}{c}0.269^{* * *} \\
{[4.05]}\end{array}$ \\
\hline REPAYI $_{i, t}$ & $\begin{array}{l}- \\
-\end{array}$ & $\begin{array}{c}0.112^{* * *} \\
{[3.04]}\end{array}$ & $\begin{array}{l}0.059 \\
{[1.04]} \\
\end{array}$ & $\begin{array}{c}0.144^{* *} \\
{[2.48]}\end{array}$ & $\begin{array}{c}0.166^{* * *} \\
{[2.72]}\end{array}$ \\
\hline $\mathrm{CAPII}_{i, t}$ & $\begin{array}{l}- \\
-\end{array}$ & $\begin{array}{l}- \\
-\end{array}$ & $\begin{array}{l}0.079 \\
{[1.26]}\end{array}$ & $\begin{array}{c}0.415^{* * *} \\
{[4.13]}\end{array}$ & $\begin{array}{c}0.384^{* * *} \\
{[3.69]}\end{array}$ \\
\hline $\operatorname{SCALI}_{i, t}$ & $\begin{array}{l}- \\
-\end{array}$ & $\begin{array}{l}- \\
-\end{array}$ & $\begin{array}{l}- \\
-\end{array}$ & $\begin{array}{c}-0.357^{* * *} \\
{[-4.19]}\end{array}$ & $\begin{array}{c}-0.313^{* * *} \\
{[-3.37]}\end{array}$ \\
\hline $\operatorname{ABORDI}_{i, t}$ & $\begin{array}{l}- \\
-\end{array}$ & $\begin{array}{l}- \\
-\end{array}$ & $\begin{array}{l}- \\
-\end{array}$ & $\begin{array}{l}- \\
-\end{array}$ & $\begin{array}{l}-0.098 \\
{[-1.19]}\end{array}$ \\
\hline CONS & $\begin{array}{c}0.314^{* * *} \\
{[26.46]}\end{array}$ & $\begin{array}{c}0.309^{* * *} \\
{[26.16]}\end{array}$ & $\begin{array}{c}0.307^{* * *} \\
{[25.93]}\end{array}$ & $\begin{array}{c}0.298^{* * *} \\
{[25.46]}\end{array}$ & $\begin{array}{c}0.299^{* * *} \\
{[25.43]}\end{array}$ \\
\hline $\begin{array}{l}\text { Industry } \\
\text { Year } \\
R^{2} \\
F \text {-test }\end{array}$ & $\begin{array}{c}\text { Control } \\
\text { Control } \\
0.139 \\
234.18^{* * *} \\
\end{array}$ & $\begin{array}{c}\text { Control } \\
\text { Control } \\
0.171 \\
210.57^{* * *} \\
\end{array}$ & $\begin{array}{c}\text { Control } \\
\text { Control } \\
0.177 \\
205.76^{* * *} \\
\end{array}$ & $\begin{array}{c}\text { Control } \\
\text { Control } \\
0.234 \\
221.06^{* * *} \\
\end{array}$ & $\begin{array}{c}\text { Control } \\
\text { Control } \\
0.239 \\
135.32^{* *} \\
\end{array}$ \\
\hline
\end{tabular}

Note: (1) the value in [] is the $t$ statistic value of the regression coefficient, all tables are the same; (2) ${ }^{* * *},{ }^{* *}$, and ${ }^{*}$ indicate significance at the significance level of $1 \%, 5 \%$, and $10 \%$, respectively, and all tables are the same.

are significantly positive, indicating that capital stock and factor returns have a positive role in promoting the dominant comparative advantage of manufacturing. That is, both are also conducive for enhancing the competitiveness of manufacturing GVC. The estimated coefficient of SCAIL ${ }_{i, t}$ is always significantly negative, indicating that the increase in export scale does not significantly impact the competitiveness of manufacturing GVC. It also reflects from the side that China is a manufacturing country rather than a manufacturing power. It is impractical for the scale of export to expand the competitive advantage of the manufacturing value chain.

5.2.2. Inspection by Classification of Digital Input Source. The above discussion is based on the perspective of global digital input. It should be noted that the economies of scale and scope brought about by different digital inputs may be different, which may change the competitiveness GVC of the manufacturing industry in different ways. Thus, in order to distinguish the impact of various digital inputs on the competitiveness of manufacturing GVCs, this section classifies global digital inputs by source and industry type. Digital input is divided into domestic digital input and international digital input according to the source of origin. According to the type of industry, it is divided into digital input in telecommunications, digital input in software and information technology services, and digital input in electronic communications and optical manufacturing. The empirical results obtained are shown in Table 4.

In Table 4, column (6) and column (7) are the estimated results of formulas (18) and (19), respectively. We can find that the estimated coefficients of CHN_DIGI ${ }_{i, t}$ and INT_DIGI $_{i, t}$ are all positive and pass the $1 \%$ significance test. This result shows that domestic digital investment and international digital investment have a significant, positive role in promoting the manufacturing industry's apparent comparative advantage, which means that increasing the integration of manufacturing with domestic and foreign digitalization will enhance the industry's GVC competitiveness.

Further, based on the empirical test results, it can be found that the estimated coefficient of INT_DIGI ${ }_{i, t}$ is significantly larger than the estimated coefficient of CHN_DIGI ${ }_{i, t}$, indicating that the positive effect of using international digital input in manufacturing is greater than the positive effect of using 
TABLE 4: Estimated results by the source of input.

\begin{tabular}{|c|c|c|c|c|c|}
\hline Variable & (6) & (7) & (8) & (9) & (10) \\
\hline \multirow{2}{*}{ CHN_DIGI ${ }_{i, t}$} & $0.247^{* * *}$ & - & - & - & - \\
\hline & [3.83] & - & - & - & - \\
\hline \multirow{2}{*}{ INT_DIGI ${ }_{i, t}$} & - & $0.305^{* * *}$ & - & - & - \\
\hline & - & {$[4.98]$} & - & - & - \\
\hline \multirow{2}{*}{ TELE_DIGI $_{i, t}$} & - & - & $0.139^{* * *}$ & - & - \\
\hline & - & - & [3.08] & - & - \\
\hline \multirow{2}{*}{ SOFT_DIGI ${ }_{i, t}$} & - & - & - & $0.283^{* * *}$ & - \\
\hline & - & - & - & [4.27] & - \\
\hline \multirow{2}{*}{ POST_DIGI $_{i, t}$} & - & - & - & - & $0.152^{* * *}$ \\
\hline & - & - & - & - & [5.35] \\
\hline \multirow{2}{*}{$\operatorname{REPAYI}_{i, t}$} & $0.166^{* * *}$ & $0.223^{* * *}$ & $0.197^{* * *}$ & $0.191^{* * *}$ & $0.147^{* * *}$ \\
\hline & {$[2.70]$} & [3.79] & [3.24] & [3.19] & {$[2.47]$} \\
\hline \multirow{2}{*}{$\mathrm{CAPII}_{i, t}$} & $0.379^{* * *}$ & $0.281^{* * *}$ & 0.078 & $0.301^{* * *}$ & $0.190^{* * *}$ \\
\hline & {$[3.62]$} & {$[2.93]$} & {$[0.71]$} & {$[3.07]$} & {$[2.00]$} \\
\hline $\operatorname{SCALI}_{i, t}$ & $\begin{array}{c}-0.313^{* * * *} \\
{[-3.36]}\end{array}$ & $-0.256^{* * *}$ & $\begin{array}{l}-0.120 \\
\end{array}$ & $\begin{array}{l}-0.260^{* * *} \\
{[-283]}\end{array}$ & $\begin{array}{c}-0.269^{* * *} \\
{[-299]}\end{array}$ \\
\hline \multirow{2}{*}{$\operatorname{ABORDI}_{i, t}$} & -0.083 & $-0.145^{*}$ & -0.028 & -0.134 & -0.021 \\
\hline & {$[-1.01]$} & {$[-1.75]$} & {$[-0.36]$} & {$[-1.56]$} & {$[-0.29]$} \\
\hline \multirow{2}{*}{ CONS } & $0.299^{* * *}$ & $0.300^{* * *}$ & $0.301^{* * *}$ & $0.298^{* * *}$ & $0.299^{* * *}$ \\
\hline & {$[25.34]$} & [25.92] & {$[25.18]$} & [25.37] & {$[25.96]$} \\
\hline Industry & Control & Control & Control & Control & Control \\
\hline Year & Control & Control & Control & Control & Control \\
\hline$R^{2}$ & 0.233 & 0.264 & 0.217 & 0.244 & 0.274 \\
\hline$F$-test & $134.96^{* * *}$ & $143.89^{*}$ & $158.58^{* * *}$ & $141.39^{* * *}$ & $156.78^{* * *}$ \\
\hline
\end{tabular}

domestic digital input. And, it means that international digital input is more conducive for enhancing the competitiveness of manufacturing GVC.

The reason is that the GVC division of labor system involves trade activities in various regions of the world, and international digital investment is more conducive for building bridges for international trade activities and providing more efficient services. Column (8), column (9), and column (10) are the estimated results of formulas (20), (21), and (22), respectively. It can be found that the estimated coefficients of TELE_DIGI $i, t$, SOFT_DIGI ${ }_{i, t}$, and POST_$\mathrm{DIGI}_{i, t}$ are all positive and pass the $1 \%$ significance test, indicating that the digital input in the telecommunications industry, the digital input in the software and information technology service industry, and the digitalization in the electronic communication and optical manufacturing industries. All inputs have a significant positive role in promoting the dominant comparative advantage of the manufacturing industry, which means that different types of digital inputs are all conducive for enhancing the GVC competitive advantage of China's manufacturing industry and realizing a rise in GVC. Further analysis found that the estimated coefficient of SOFT_DIGI ${ }_{i, t}$ is greater than the estimated coefficients of the other two, informing that the digital investment of software and information technology service industry has the greatest effect on the improvement of manufacturing GVC competitiveness. The reason is that the software and information technology service industry is the more critical production factor in the international division of labor system. The reason behind this is quite obvious, including that its technology is updated quickly, the application field is wide, the penetration ability is strong, the resource consumption is low, and it can realize the full use of human resources.

5.2.3. Inspection by Industry Type. The above discussion is based on the manufacturing industry as a whole. In order to further distinguish between different types of industries, this section divides the manufacturing industry into lowknowledge-intensive industries, low- and medium-knowledge-intensive industries, and medium- and high-knowledgeintensive-industries. It examines the impact of digitalization on the GVC; the results obtained are shown in Table 5.

In Table 5, column (11), column (12), and column (13) correspond to the estimation results of low-knowledge-intensive industries, low- and medium-knowledge-intensive industries, and medium- and high-knowledge-intensive industries, respectively. It can be seen from Table 5 that GLO_DIGI ${ }_{i, t}$ has significant differences in promoting GVC competitiveness in different types of industries. In lowknowledge-intensive industries, the estimated coefficient of GLO_DIGIi,t is not significant, indicating that digital investment does not significantly impact the GVC competitiveness of this type of industry, which indicates that it is unlikely that we want to enhance GVC competitiveness by increasing the digital scale of low-knowledge-intensive industries. The reason is that low-knowledge-intensive industries are labor-intensive but at the same time have considerable labor comparative advantages. It is not easy to embed digital technology in this type of 
TABLE 5: Estimated results by industry type.

\begin{tabular}{|c|c|c|c|}
\hline Variable & $(11)$ & $(12)$ & (13) \\
\hline GLO_DIGI $_{i, t}$ & $\begin{array}{c}-45.929 \\
{[-1.44]}\end{array}$ & $\begin{array}{c}8.232^{* * *} \\
{[3.05]}\end{array}$ & $\begin{array}{c}0.242^{* *} \\
{[2.06]}\end{array}$ \\
\hline $\operatorname{REPAYI}_{i, t}$ & $\begin{array}{c}-0.188 \\
{[-0.35]}\end{array}$ & $\begin{array}{c}0.430^{* * *} \\
{[4.68]}\end{array}$ & $\begin{array}{c}-0.320^{* * *} \\
{[-3.61]}\end{array}$ \\
\hline $\mathrm{CAPII}_{i, t}$ & $\begin{array}{c}2.023^{* * *} \\
{[4.08]}\end{array}$ & $\begin{array}{c}0.426^{* *} \\
{[2.47]} \\
\end{array}$ & $\begin{array}{c}0.972^{* * *} \\
{[3.29]}\end{array}$ \\
\hline $\operatorname{SCALI}_{i, t}$ & $\begin{array}{l}-1.877 \\
{[-3.08]}\end{array}$ & $\begin{array}{c}-0.227^{* * *} \\
{[-2.31]} \\
\end{array}$ & $\begin{array}{c}-0.448^{* *} \\
{[-2.37]}\end{array}$ \\
\hline $\mathrm{ABORDI}_{i, t}$ & $\begin{array}{c}0.958^{* *} \\
{[2.37]}\end{array}$ & $\begin{array}{c}-0.436^{* * *} \\
{[-3.07]}\end{array}$ & $\begin{array}{l}0.157^{*} \\
{[1.72]} \\
\end{array}$ \\
\hline CONS & $\begin{array}{c}0.384^{* * *} \\
{[12.42]}\end{array}$ & $\begin{array}{c}0.298^{* * *} \\
{[22.40]}\end{array}$ & $\begin{array}{c}0.146^{* * *} \\
{[12.11]}\end{array}$ \\
\hline $\begin{array}{l}\text { Industry } \\
\text { Year } \\
R^{2} \\
F \text {-test }\end{array}$ & $\begin{array}{c}\text { Control } \\
\text { Control } \\
0.373 \\
99.29^{* * *}\end{array}$ & $\begin{array}{c}\text { Control } \\
\text { Control } \\
0.565 \\
146.89^{* * *}\end{array}$ & $\begin{array}{c}\text { Control } \\
\text { Control } \\
0.877 \\
230.76^{* * *}\end{array}$ \\
\hline
\end{tabular}

industry, and the dividends brought about by digitalization are not enough to make up for the labor competitive advantage that it reduces by replacing labor. Correspondingly, the estimated coefficients of GLO_DIGI ${ }_{i, t}$ are significantly positive in the low-medium and medium-high knowledge-intensive industries, indicating that digital investment has a significant role in promoting the GVC competitiveness of these two types of industries. And medium-to-high knowledge-intensive industries can increase GVC competitiveness by increasing industry digital investment. Compared with low-knowledge-intensive industries and low- and medium-knowledge-intensive industries, medium- and high-knowledge intensive-industries have lower labor intensity and higher capital and technology intensity, making it easier to achieve industry digitization and realize industrial division of labor through digitization. The improvement of synergy efficiency and the substantial reduction of production costs will consume labor cost advantages to a lesser extent, making the positive effects of digitalization greater than the negative effects.

5.2.4. Robustness Test. In order to test whether the above empirical results are robust and whether the impact of digitization on the competitiveness of manufacturing GVC is positive, the following robustness tests are carried out in this paper. The regression results are shown in Tables 4 and 6.

(1) Use Different Explanatory Variable Indicators. Replace the core explanatory variable global digital input (GLO_DIGI ${ }_{i, t}$ ) with domestic digital input $\left(\mathrm{CHN} \_\mathrm{DIGI} \mathrm{I}_{i, t}\right)$ and international digital input $\left(\mathrm{INT}_{-} \mathrm{DIGI}_{i, t}\right)$. The estimation results are shown in column (6) and column (7) in Table 4 . It can be seen that the estimated coefficients of CHN_DIGI ${ }_{i, t}$ and INT_DIGI $_{i, t}$ are positive, and the significance is consistent with the coefficients using GLO_DIGI $i, t$, thus verifying the robustness of the conclusion.
(2) Increase Control Variables. Some studies have suggested an effective way to enhance the core competitiveness of enterprises by increasing labor productivity and ability to innovate way. In order to reduce the estimation bias caused by the lack of control variables, combined with the availability of data, this paper adds industry $\mathrm{R} \& \mathrm{D}$ expenditure and industry per capita output as control variables to measure industry innovation capability (RD) and labor productivity (PRD) $[33,34]$. The regression results are shown in column (14) in Table 6. It can be seen that the sign and significance of the estimated coefficients of the core explanatory variables have not changed substantially, thus verifying the robustness of the conclusions.

(3) Use Different Explained Variable Indicators. The GVC position index (GVC_POS) proposed by Wang et al. replaces GVC_RCA [35]. The GVC position index is used to measure the GVC division of labor status of a certain industry in a country. The larger the index, the higher the international division of labor status the country is in, and vice versa. The regression results are shown in column (15) of Table 6 . It can be seen that the estimated coefficients of GLO_DIGI ${ }_{i, t}$ are significantly positive, indicating that digital investment is beneficial for the promotion of the GVC division of labor status in the manufacturing industry, thus verifying the robustness of the conclusion.

(4) Endogenous Testing. In order to solve the possible endogeneity and causality in the model, the core explanatory variables are lagging by one period, respectively, using GLO_DIGIi,t lagging by one period re-regression, and two-stage least squares (2SLS) re-regression. The regression results are shown in column (16) and column (17) in Table 6. The results show that the sign and significance of the estimated coefficients of the core explanatory variables concerned in this paper have not changed 
TABle 6: Robustness test.

\begin{tabular}{|c|c|c|c|c|}
\hline Variable & (14) & (15) & (16) & (17) \\
\hline GLO_DIGI $_{i, t}$ & $\begin{array}{c}0.245^{* * *} \\
{[3.71]}\end{array}$ & $\begin{array}{c}0.153^{* *} \\
{[2.18]}\end{array}$ & - & $\begin{array}{c}0.195^{* * *} \\
{[3.16]}\end{array}$ \\
\hline L .GLO_DIGI ${ }_{i, t}$ & $\begin{array}{l}- \\
- \\
\end{array}$ & $\begin{array}{l}- \\
-\end{array}$ & $\begin{array}{c}0.203^{* * *} \\
{[2.94]} \\
\end{array}$ & $\begin{array}{l}- \\
-\end{array}$ \\
\hline $\operatorname{REPAYI}_{i, t}$ & $\begin{array}{c}0.218^{* * *} \\
{[2.94]} \\
\end{array}$ & $\begin{array}{c}-0.263^{* * *} \\
{[-4.10]}\end{array}$ & $\begin{array}{c}0.189^{* * * *} \\
{[3.21]} \\
\end{array}$ & $\begin{array}{c}0.165^{* * *} \\
{[3.14]} \\
\end{array}$ \\
\hline $\mathrm{CAPII}_{i, t}$ & $\begin{array}{c}0.546^{* * *} \\
{[4.96]} \\
\end{array}$ & $\begin{array}{c}0.364^{* * *} \\
{[3.32]} \\
\end{array}$ & $\begin{array}{c}0.363^{* * *} \\
{[3.61]} \\
\end{array}$ & $\begin{array}{c}0.439^{* * * *} \\
{[5.27]}\end{array}$ \\
\hline $\operatorname{SCALI}_{i, t}$ & $\begin{array}{c}-0.636^{* * *} \\
{[-5.65]} \\
\end{array}$ & $\begin{array}{c}0.151 \\
{[1.54]} \\
\end{array}$ & $\begin{array}{c}-0.328^{* * *} \\
{[-3.71]} \\
\end{array}$ & $\begin{array}{c}-0.386^{* * *} \\
{[-5.37]} \\
\end{array}$ \\
\hline $\mathrm{ABORDI}_{i, t}$ & $\begin{array}{l}0.060 \\
{[0.64]} \\
\end{array}$ & $\begin{array}{l}-0.083 \\
{[-0.95]}\end{array}$ & $\begin{array}{l}-0.065 \\
{[-0.81]} \\
\end{array}$ & $\begin{array}{l}-0.022 \\
{[-0.32]} \\
\end{array}$ \\
\hline $\mathrm{RD}_{i, t}$ & $\begin{array}{c}0.091^{* *} \\
{[2.14]}\end{array}$ & $\begin{array}{l}- \\
-\end{array}$ & $\begin{array}{l}- \\
-\end{array}$ & $\begin{array}{l}- \\
- \\
\end{array}$ \\
\hline $\mathrm{PRD}_{i, t}$ & $\begin{array}{c}0.204^{* * *} \\
{[3.92]} \\
\end{array}$ & $\begin{array}{l}- \\
- \\
\end{array}$ & $\begin{array}{l}- \\
- \\
\end{array}$ & - \\
\hline CONS & $\begin{array}{c}0.319^{* * *} \\
{[25.81]}\end{array}$ & $\begin{array}{c}0.363^{* * *} \\
{[29.26]}\end{array}$ & $\begin{array}{c}0.284^{* * * *} \\
{[14.86]}\end{array}$ & $\begin{array}{l}- \\
-\end{array}$ \\
\hline $\begin{array}{l}\text { Industry } \\
\text { Year }\end{array}$ & $\begin{array}{l}\text { Control } \\
\text { Control }\end{array}$ & $\begin{array}{l}\text { Control } \\
\text { Control }\end{array}$ & $\begin{array}{l}\text { Control } \\
\text { Control }\end{array}$ & $\begin{array}{l}\text { Control } \\
\text { Control }\end{array}$ \\
\hline$R^{2}$ & 0.299 & 0.270 & 0.233 & 0.228 \\
\hline$F$-test & $109.86^{* * *}$ & $143.20^{* * *}$ & $139.99^{* * *}$ & $2262.68^{* * *}$ \\
\hline Anderson-Rubin Wald test & - & - & - & $9.86^{* * *}$ \\
\hline Cragg-Donald Wald $F$ statistic & - & - & - & 2258.87 \\
\hline
\end{tabular}

Note: column (17) in the Table is estimated by using the 2SLS method under fixed effect and $F$-test as the first-stage $F$ value.

substantially, thus verifying the robustness of the conclusions.

5.2.5. Intermediary Effect Test. According to the mechanism analysis of the theoretical model, it can be seen that digitization can reduce the transaction and production cost of enterprises through cost effect, improve the efficiency of the labor force in the production division of labor through allocation effect and synergy effect, and expand the competitive advantage of the industry. To this end, this paper uses the Bootstrap mediation effect test method proposed by Wen and Ye to test the conduction path [36]. Combined with data availability, this paper takes industrial labor productivity as an intermediary variable, and the test results are shown in Table 7. It can be seen from Table 7 that the estimated coefficients of Bootstrap's direct effects and indirect effects are both positive, and they have passed the $1 \%$ and $5 \%$ significance tests, respectively, indicating that the mediating effect of labor productivity is significant, which means that digitalization can improve industrial labor productivity to achieve the improvement of GVC competitiveness. At the same time, it proves that the positive effect of digitalization on the competitiveness of manufacturing GVC is robust.

\section{Findings and Policy Implications}

This paper uses the panel data in WIOD to calculate the GVC explicit comparative advantage index of China's manufacturing industry through the WWZ method, analyzes the impact of manufacturing digitization on the competitiveness of the value chain from the perspectives of mechanism analysis and empirical testing, and examines the results of the robustness test. The main conclusions are as follows: First, through the reconstruction of manufacturing GVC competitiveness, it is found that the overall GVC competitiveness of China's manufacturing industry shows a two-stage trend of rising and falling, and the second stage is weaker than the first stage, and an overall improvement has been achieved. In terms of industries, the competitiveness of GVC is different. The low- and medium-knowledge-intensive industries are the strongest, followed by the lowknowledge-intensive industries, and the medium- and highknowledge-intensive industries are the weakest, and some industries are seriously lacking in competitiveness. Second, digital investment has a significant positive role in promoting the competitiveness of manufacturing GVC. In terms of digital input from different sources, the positive effect is still substantial. The positive effect of the international digital input is greater than that of the domestic one. The positive effect of software and information technology service industries is greater than that of telecommunications, electronic communications, and optical manufacturing. Third, in different knowledge-intensive industries, the effects of digitalization show differences. In low-knowledge-intensive industries, the positive effects of digitalization are not significant. In both low- and medium- and medium- and high-knowledge-intensive industries, digitalization can significantly improve the industry's GVC competitiveness. 
TABLE 7: Bootstrap intermediary effect test.

\begin{tabular}{|c|c|c|c|c|c|c|}
\hline Variable & Observed coef. & Bootstrap std.err. & $z$ & $P>|z|$ & \multicolumn{2}{|c|}{$\begin{array}{l}\text { Normal-based } \\
\text { [95\% conf. } \\
\text { interval }]\end{array}$} \\
\hline Indirect effects of labor productivity & 0.026 & 0.002 & 14.98 & $\leq 0.001$ & 0.023 & 0.030 \\
\hline Direct effects & 0.245 & 0.115 & 2.13 & 0.033 & 0.019 & 0.470 \\
\hline
\end{tabular}

Fourth, the mediation effect test shows that labor productivity is an effective way to enhance the competitiveness of China's manufacturing GVC digitally.

The conclusion of this paper provides a certain empirical reference for the digital development of the Chinese manufacturing industry from the perspective of value chain competitiveness. The core point of this paper is that in the process of promoting the digitization of the manufacturing industry actively, we must not only avoid the generalization of different sources and different types of digital input but also avoid generalizing of different knowledge-intensive industries. It mainly includes the following two points:

First, develop digital infrastructure construction vigorously and reduce the threshold of digital investment in manufacturing. An external condition for increasing the manufacturing industry's digital input to enhance the competitiveness of GVC is that a country has advanced with a large-scale digital infrastructure. This condition requires the government to increase the financial investment in the construction of digital infrastructure, upgrade high-precision digital technology, reduce digital input cost in the industry, and help popularize digital applications in the industry.

Second, the promotion of manufacturing digitization needs to follow the digital input and industry differences. In the process of increasing the digital input of the manufacturing industry, it is not only necessary to focus on domestic digital input but also on international digital input. At the same time, digitalization should be selectively embedded in different types of industries in order to maximize the utility of digitization, such as more embedded digitization in both low- and medium- and medium- and high-knowledge-intensive industries, and digital investment should be reduced in low-knowledgeintensive industries.

\section{Data Availability}

Data are available from the China ICT Institute's White Paper on China's Digital Economic Development (2020 Edition), in https://www.caict.ac.cn/kxyj/qwfb/bps/202007/ P020200703318256637020.pdf. Here, we learn from He's manufacturing industry classification method and classify the subindustries according to their knowledge intensity. Among them, low-knowledge-intensive industries include C05, C06, C07, C08, C09, medium- and low-knowledgeintensive industries include C10, C11, C12, C13, C14, C15, $\mathrm{C} 16, \mathrm{C} 22$, medium-, and high-knowledge-intensive industries include C17, C18, C19, C20, C21.

\section{Conflicts of Interest}

The authors declare that there are no conflicts of interest regarding the publication of this paper.

\section{Acknowledgments}

This study was funded by the major projects of the National Social Science Fund (Grant No. 15ZDA009), Anhui Natural Science Foundation Project (Grant Nos. 1808085MG218; 1908085MG231) Support Plan for Outstanding Young Talents in Colleges and Universities in 2019 (Grant No. gxyq2019024), 2020 Anhui Provincial Federation of Social Sciences Research Projects (Grant No. 2020CX066), and Anhui University of Finance and Economics School-Level Scientific Research Fund Project (Grant No. ACYC2019154).

\section{References}

[1] H. L. Zhu and C. J. Wang, "Digital economy leads high-quality development of industry: theory, mechanism and path," The Theory and Practice of Finance and Economics, vol. 41, no. 5, pp. 2-10, 2020.

[2] X. Y. Qiao, G. Wang, and Z. Y. Li, "Review of domestic and foreign research on global value chains: an analysis based on SCI/SSCI/CSSCI literature," Asia-Pacific Economic Review, vol. 1, pp. 116-126, 2017.

[3] D. Hummels, J. Ishii, and K.-M. Yi, "The nature and growth of vertical specialization in world trade," Journal of International Economics, vol. 54, no. 1, pp. 75-96, 2001.

[4] R. Koopman, Z. Wang, and S. J. Wei, "Estimating domestic content in exports when processing trade is pervasive," Journal of Development Economics, vol. 99, no. 1, pp. 178-189, 2012.

[5] Z. Wang, S. J. Wei, and F. K. Zhu, "Total trade accounting: official trade statistics and measurement of global value chains," Social Sciences in China, vol. 9, pp. 108-206, 2015.

[6] S. J. Zhang and Z. B. Liu, "Industrial upgrading and balanced development of area: from global value chain to national value chain," Business Management Journal, vol. 35, no. 8, pp. 3040, 2013.

[7] S. Basco and M. Mestieri, "The world income distribution: the effects of international unbundling of production," Journal of Economic Growth, vol. 24, no. 2, 2019.

[8] R. Zhao, L. X. Zhao, and Y.X. Su, "Global value chain, regional integration development and manufacturing industry upgrading: thoughts on the dual circulation new development pattern," South China Journal of Economics, vol. 10, pp. 1-19, 2020.

[9] J. R. Baldwin and B. Yan, Global Value Chain Participation and the Productivity of Canadian Manufacturing Firms, Institute for Research on Public Policy, Montreal, Canada, 2016.

[10] T. J. Sturgeon, "Mapping integrative trade: conceptualising and measuring global value chains," International Journal of 
Technological Learning, Innovation and Development, vol. 1, no. 3, pp. 237-257, 2008.

[11] B. Sheng and W. T. Zhao, "Regional global value chain, market fragmentation and industrial upgrading: an analysis from the perspective of spatial spillover," Finance \& Trade Economics, vol. 41, no. 9, pp. 131-145, 2020.

[12] E. Brynjolfsson and L. M. Hitt, "Beyond computation: information technology, organizational transformation and business performance," Journal of Economic Perspectives, vol. 14 , no. 4 , pp. $23-48,2000$.

[13] L. Li, F. Su, W. Zhang, and J. Y. Mao, "Digital transformation by SME entrepreneurs: a capability perspective," Information Systems Journal, vol. 28, no. 1, pp. 1-29, 2017.

[14] J. Manyika and C. Roxburgh, "The great transformer: The impact of the internet on economic growth and prosperity," McKinsey Quarterly, no. 2, pp. 1-11, 2011.

[15] B. S. G. Pató, Z. Kovács, and L. Szabó, "Examination of ethical procurement through enterprise examples," Problems of Management in the 21st Century, vol. 11, no. 2, pp. 107-123, 2016.

[16] Z. Z. Du and J. X. Du, "The reconstruction of global value chain in the background of the fourth industrial revolution and China's countermeasures," Economic Review Journal, vol. 4, pp. 110-115, 2017.

[17] Y. L. Shen and X. M. Jin, "Digital products, global value chain and international trade rules," Journal of Shanghai Normal University (Philosophy \& Social Sciences Edition), vol. 46, no. 1, pp. 90-99, 2017.

[18] W. B. He, "Countermeasures for digital economy to promote the upgrading of China's manufacturing industry under the visual of global-value-chain," Asia-pacific Economic Review, vol. 3, pp. 115-152, 2020.

[19] D. Acemoglu, C. Lelarge, and P. Restrepo, "Competing with robots: firm-level evidence from France," NBER, Cambridge, MA, USA, NBER Working Paper No. 26738, 2020.

[20] R. Hausmann, J. Hwang, and D. Rodrik, "What you export matters," Journal of Economic Growth, vol. 12, pp. 1-25, 2007.

[21] B. Qiu, L. F. Ye, and S. Q. Kong, "An empirical study on the impact of GPNs on China's manufacturing industries' upgrading in global value chains-an analysis from the perspective of ESI," China Industrial Economics, vol. 1, pp. 57-67, 2012.

[22] C. B. Frey and M. A. Osborne, "The future of employment: how susceptible are jobs to computerisation?" Technological Forecasting and Social Change, vol. 114, no. 1, pp. 254-280, 2017.

[23] J. F. Gao and B. Wang, "Does digital technology promote China's global value chain position," International Economics and Trade Research, vol. 36, no. 11, pp. 35-51, 2020.

[24] Y. B. Chen, C. Lin, and X. L. Chen, "Artificial intelligence, aging and economic growth," Economic Research Journal, vol. 7, pp. 47-63, 2019.

[25] Y. Lv, W. Gu, and Q. Bao, "Artificial intelligence and Chinese enterprises' participate in global value chains," China Industrial Economics, vol. 5, pp. 80-98, 2020.

[26] G. Graetz and G. Michaels, "Robots at work," The Review of Economics and Statistics, vol. 100, no. 5, pp. 753-768, 2018.

[27] A. Goldfarb and C. Tucker, "Digital economics," Journal of Economic Literature, vol. 57, no. 1, pp. 3-43, 2019.

[28] M. Ghasemaghaei and G. Calic, "Does big data enhance firm innovation competency? The mediating role of data-driven insights," Journal of Business Research, vol. 104, no. 7, pp. 69-84, 2019.
[29] K. Xie, Z. H. Xia, and J. H. Xiao, "The enterprise realization mechanism of big data becoming a real production," China Industrial Economics, vol. 5, pp. 42-60, 2020.

[30] Z. Wang, S. J. Wei, and K. Zhu, "Quantifying international production sharing at the bilateral and sector levels," NBER, Cambridge, MA, USA, NBER Working Paper, 2013.

[31] F. Y. Li, China's Manufacturing Industry and its Governance and Upgrading in the Digital Economy Era, Foreign Economic and Trade University, Beijing, China, 2018.

[32] W. B. He, "Analysis on the effect of digitalization promoting the high end of China's manufacturing value chain: from the perspective of global value chain," East China Economic Management, vol. 34, no. 12, pp. 29-38, 2020.

[33] W. T. Liu, J. H. You, and X. H. Zhou, "Industrial globalization, R\&D investment and firm performance," Economic Survey, vol. 37, no. 5, pp. 63-71, 2020.

[34] X. Chen, "Does the polycentric space structure contribute to the improvement of production efficiency?" Modern Economic Research, vol. 2, pp. 83-92, 2020.

[35] Z. Wang, S. J. Wei, X. Yu et al., "Measures of participation in global value chains and global business cycles," NBER, Cambridge, MA, USA, National Bureau of Economic Research Working Paper Series No. 23222, 2017.

[36] Z. Wen and B. Ye, "Analyses of mediating effects: the development of methods and models," Advances in Psychological Science, vol. 22, no. 5, pp. 731-745, 2014. 